Document downloaded from:

http://hdl.handle.net/10251/63030

This paper must be cited as:

Vargas, A.; Boza Garcia, A.; Patel, S.; Patel, D.; Cuenca González, ML.; Ortiz Bas, A. (2015). Risk Management in Hierarchical Production Planning Using Inter-enterprise Architecture. En Risks and Resilience of Collaborative Networks. 16th IFIP WG 5.5 Working Conference on Virtual Enterprises, PRO-VE 2015, Albi, France,, October 5-7, 2015, Proceedings. Springer. 17-26. doi:10.1007/978-3-319-24141-8_2.

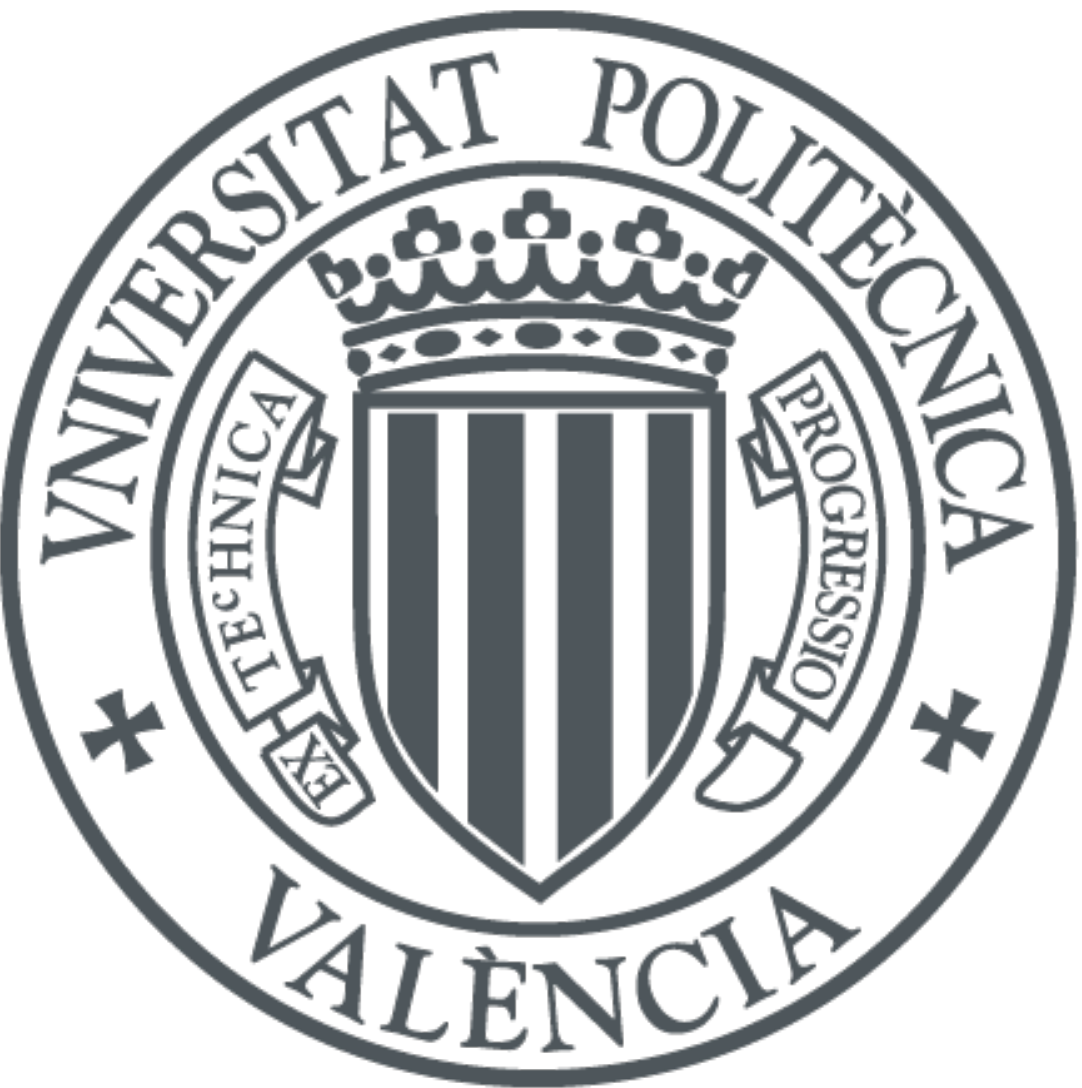

The final publication is available at

http://link.springer.com/chapter/10.1007/978-3-319-24141-8_2

Copyright Springer

Additional Information 


\title{
Risk management in hierarchical production planning using inter-enterprise architecture
}

\author{
Alix Vargas ${ }^{1}$, Andres Boza ${ }^{1}$, Shushma Patel ${ }^{2}$, Dilip Patel ${ }^{2}$, Llanos Cuenca ${ }^{1}$, Angel \\ Ortiz $^{1}$ \\ ${ }^{1}$ Centro de Investigación en Gestión e Ingeniería de Producción (CIGIP). \\ Universitat Politècnica de València. Camino de Vera s/n Ed $8 \mathrm{G}-1^{\circ}$ y $4^{\circ}$ planta Acc D \\ (Ciudad Politécnica de la Innovación) Valencia Spain. \\ alvarlo@posgrado.upv.es, \{aboza, llcuenca, aortiz\}@cigip.upv.es \\ ${ }^{2}$ London South Bank University, School of Engineering, 103 Borough Road, SE1 \\ 0AA, London, United Kingdom \\ \{shushma,dilip\}@1sbu.ac.uk
}

\begin{abstract}
Unexpected events in hierarchical production planning, such as rush orders, labor problems, lack of availability of materials and faulty machines have to be managed efficiently because they represent a risk for business continuity, based on their impact and duration. The use of inter-enterprise architecture offers multiple benefits for collaborative networks, including: business strategy and information technology alignment, joint process integration and synchronization, supply chain cost reduction, risk and redundancy minimization and customer services improvement. Therefore, the use of inter-enterprise architecture to address the problem of unexpected events in hierarchical production planning supporting operational risk management is proposed. This paper presents a model for inter-enterprise architecture that addresses the problem of handling unexpected events in hierarchical production planning and how the inter-enterprise framework is embedded into the model.
\end{abstract}

Keywords: inter-enterprise architecture, hierarchical production planning, collaborative networks, unexpected events, risk management

\section{Introduction}

The current dynamic environment forces enterprises to create collaborative networks $(\mathrm{CN})$ in order to survive and maintain a competitive advantage. Collaborative networks are manifested in a variety of forms [1]: virtual enterprises, virtual organizations, extended enterprises, virtual communities and virtual teams. Interenterprise architecture allows CNs to: integrate business processes, align business with information systems and technology, increase responsiveness, reduce risks, inventory and redundancies, create synergies to achieve common goals, minimize cost of the supply chain, among other benefits [2].

Inter-enterprise architecture can be used to approach different issues that CNs have to address on a daily basis, such as: procurement planning, production planning, 
inventory planning, scheduling and controlling, and logistics and delivery planning. In this paper, our focus is production planning and specifically hierarchical production planning that facilitates decision-making in $\mathrm{CNs}$ by decomposing the decision problem into sub-problems. The sub-problems are related to the organizational structure at the highest levels of the hierarchy imposing restrictions at the lower levels [3].

In hierarchical production planning, the use of decision support systems (DSS) has increased considerably as these systems provide decision makers with better and more accurate real time information using mathematical and optimization models [4]. However, these systems are not designed to handle unexpected events that threaten business continuity. Thus, decision makers are forced to take decisions based on their knowledge and expertise, and the original plans have to change resulting in inefficiencies, increased inventory levels and costs, reducing customer service satisfaction and even risking business continuity.

Taking into account a holistic view of hierarchical production planning and decision support needs for unexpected events handling, poses the research question: Can the use of inter-enterprise architecture solve the problem of the arrival of unexpected events in hierarchical production planning supporting operational risk management? This paper proposes a model of inter-enterprise architecture to address the problem of handling unexpected events in hierarchical production planning enabling operational risk management in $\mathrm{CNs}$ and the validation of how the interenterprise framework is mapped into this model.

The paper is structured as follows: Section 2 describes the related work in the fields of: hierarchical production planning and operational risk, decision support systems and inter-enterprise architecture, with the latter describing the main findings of the research to date. Section 3 presents the proposed model that describes the problem of handling unexpected events in hierarchical production planning to support risk management. Section 4 maps the framework proposed in our ongoing research with the risk management model. Finally Section 5 presents the main conclusions and future work.

\section{Related work}

\subsection{Hierarchical production planning and operational risk}

Collaborative and productive activities, especially planning and control, should follow a hierarchical approach that allows coordination between the objectives, plans and activities of the strategic, tactical and operational levels, in order to reduce the complexity of the system [5]. This means that each level will pursue their own goals, but take into account the higher level, on which it depends, and the lower level, which is restricted [4]. In hierarchical production planning (HPP) systems, the problems are split into sub-problems. Each sub-problem is related to a decision-making level in the organizational structure and a mathematical model is constructed for solving each 
sub-problem, which has different planning horizons, with aggregated and disaggregated information across hierarchical levels [3].

Operational risk is associated with the execution of companies' business functions. Risk management is the process devoted to protecting the organizations and augmenting its capability to achieve its stated strategic objectives [6]. In the context of production planning, the risk is associated with the arrival of unexpected events that affect the normal performance planning. Effectively preparing for unexpected events, such as the lack of available materials, rush orders, faulty machines, etc., is vital to guaranteeing business continuity. Therefore, the ability to cope with these changes and helping decision makers react in the best way, are important issues that must be taken into account in the systems and planning processes. Some studies have proposed that manufacturing systems should be sufficiently flexible and robust in order to efficiently handle unexpected events $[7,8]$ and new proposals arise for a better information management in production, such as Internet of Things [9]. However, most of the work in these areas only considers certain types of unexpected events, or provides limited assistance to manage how people react to them. There is limited research that takes into account the management of different types of unexpected events in an integrated way.

Darmoul et al [7], define a typology of the different kinds of unexpected events that can occur in a manufacturing system and therefore affect production planning. This typology states that unexpected events could originate from the following entities: suppliers, resources, production and customers. The specific events reported for each kind of origin are:

-In suppliers: delays, difference in quantity ordered and quality problems

-In resources: machine breakdowns, tools breakage, workers sickness, workers under performance, workers high performance and strike

-In production: low raw material utilization, high raw material utilization, quality problems, low performance in production, high performance in production, returns for low quality, returns for delay in delivery and refunds for early delivery

-In customers: rush orders, order modification and order cancelation

In order to manage each and every specific unexpected event in an integrated way, it is necessary to consider different factors for its management, such as, duration of the disturbance (estimation of how long an unexpected event can last) and the criticality of the resources involved (which relates to substitution of resources), as well as the impact (high: related to strategic decisions, or low: related to operational or tactical decisions).

\subsection{Decision support systems and hierarchical production planning}

Information systems, which provide necessary information for managers to make decisions, have become key elements in the decision-making process. Therefore, decision support systems are indispensable tools not only to obtain an optimal solution, but also to obtain a broader and deeper understanding of the problem.

A hierarchical production planning system should be able to detect abnormal behaviour, determine the type of disruption and continually propose alternatives 
depending on the type of event. Determining the type of unexpected event is important because the process will be affected differently and will require different decisions to be made. In this context, the way the decision maker understands the information can accelerate his/her perception, provide better insight and control, and harness the large volume of valuable data to gain a competitive advantage by making improved decisions [10].

Hierarchical production planning systems need to be sufficiently flexible in order to adapt to dynamic environments. The area of flexibility within the context of hierarchical production planning systems has been studied and different solutions proposed [11,12], which demonstrate how the data model can be integrated with the hierarchical planning system. In addition, Boza et al. [4] state the logical building blocks that play an interactive role in the information system and decision technologies for hierarchical production planning, which are: Data Modelling (DaM), which represents the internal structure and the external presentation of the data; Decision Modelling (DeM) defines the models that represent the problem to be addressed. These models are used to evaluate possible decisions in a problem domain; and Model Analysis and Research (MAR), which is the instantiation of the decision model with data, model evaluation and results.

To date, there is little evidence of research using decision support systems for hierarchical production planning that includes handling unexpected events allowing for business continuity. Therefore, the ongoing research of inter-enterprise architecture aims to address this gap.

\subsection{Inter-enterprise architecture}

In our ongoing research, the concept of inter-enterprise architecture (IEA) has been proposed by investigating the application of enterprise architecture in CNs [13]. The main elements of inter-enterprise architecture are: framework, methodology, and modelling language [2]. The framework represents a simple, graphical structure of the elements that make up the enterprise [14] and shows how the elements are integrated and related. The modelling language allows for modelling, organizing and understanding the relationships between elements of the enterprise, using building blocks to describe them [15]. The methodology facilitates the implementation of the framework, step-by-step, through the use of the building blocks defined by the modelling language [16].

Vargas et al. [17] proposed a framework for IEA comprising of four life cycle phases (identification, conceptualization, definition and action plan) and seven modelling views (business, organization, resources, process, decision, data and IS/IT). The framework is also represented by its eighteen building blocks, which constitute the modelling language proposed. The extended and revised framework and its building blocks are illustrated in Table 1 .

In proposing a useful framework for modelling an inter-enterprise architecture, to facilitate unexpected events management on hierarchical production planning, IE-GIP (the Spanish acronym that translates to 'Enterprise Integration - Business Processes and Integrated Management') [18] is the foundation of the general framework used to 
propose a partial framework to solve this problem. The proposed partial framework maintains the life cycle phases of IE-GIP adapted to the specific context and the modelling views have been merged, added or evolved as it is explained in [17].

Table 1. Definition framework of IEA and building blocks

\begin{tabular}{|c|c|c|c|c|c|c|c|}
\hline $\begin{array}{l}\text { Modelling views } \\
\text { Life cycle phases }\end{array}$ & Business & Organization & Resources & Process & Decision & Data & IS/TT \\
\hline Identification & $\begin{array}{l}\text { Domain } \\
\text { Stakeholder }\end{array}$ & $\begin{array}{l}\text { Cell } \\
\text { Unit }\end{array}$ & Worker & & & & \\
\hline Conceptualization & $\begin{array}{l}\text { Business strategy } \\
\text { Stakeholder }\end{array}$ & $\begin{array}{l}\text { Cell } \\
\text { Unit }\end{array}$ & Worker & & & & ISIT strategy \\
\hline Definition & $\begin{array}{l}\text { Objetive } \\
\text { Performance } \\
\text { assessment } \\
\text { Stakeholder }\end{array}$ & $\begin{array}{l}\text { Cell } \\
\text { Unit }\end{array}$ & $\begin{array}{l}\text { Resource } \\
\text { Worker }\end{array}$ & $\begin{array}{l}\text { AS-IS processes } \\
\text { CN processes } \\
\text { Unexpected } \\
\text { events }\end{array}$ & $\begin{array}{l}\text { Decision } \\
\text { model }\end{array}$ & $\begin{array}{l}\text { Data } \\
\text { model }\end{array}$ & $\begin{array}{l}\text { Portfolio app } \\
\text { AS-IS } \\
\text { Portfolio app } \\
\text { CN } \\
\text { Analysis model }\end{array}$ \\
\hline Action plan & $\begin{array}{l}\text { Performance } \\
\text { assessment } \\
\text { Stakeholder }\end{array}$ & $\begin{array}{l}\text { Cell } \\
\text { Unit }\end{array}$ & $\begin{array}{l}\text { Resource } \\
\text { Worker }\end{array}$ & $\begin{array}{l}\text { CN processes } \\
\text { Unexpected } \\
\text { events }\end{array}$ & $\begin{array}{l}\text { Decision } \\
\text { model }\end{array}$ & $\begin{array}{l}\text { Data } \\
\text { model }\end{array}$ & $\begin{array}{l}\text { Portfolio app } \\
\mathrm{CN} \\
\text { Analysis model }\end{array}$ \\
\hline
\end{tabular}

Through this framework, we believe it is possible to use inter-enterprise architecture for modelling the problem of handling unexpected events in hierarchical production planning. In order to validate this assertion, the next section describes the risk management model for hierarchical production planning and Section 4 illustrates how the framework is mapped to the risk management model.

\section{Proposed risk management model for HPP}

Collaborative networks have to handle different kinds of unexpected events in hierarchical production planning, which can originate from: suppliers, customers, resources or production. In this section, the risk management model for HPP is presented taking into account a collaborative network made up of 2 companies, having two levels of decisions: Planning (strategic and tactical) and operational. The planning level is supported by the planning DSS (PDSS) that provides companies with information on quantities to produce per period, quantities to buy, stock levels, etc. Unexpected events occur at the operational level and the decision maker needs to analyse the information and propose solutions to solve the problems that arise. The decision maker needs to use his/her own expertise and knowledge to solve the specific situation causing inefficiencies, bottlenecks and chaos. In order to provide support to the decision maker, the ideal operational DSS (ODSS) would provide alternative solutions depending on the event and its duration and impact. Figure 1 shows the proposed model, which represents our vision of how events should be handled, 
supported by ODSS that allows enterprises to have contingency plans showing the decision maker ways to manage specific events through rules or models that check the events' impact and analyse historical data stored in the data warehouse. The numbers in the model below represent the order in which processes occur and are described below:

1) The upper level is the planning level that sends to the operational level production plans.

2) The risk for the arrival of unexpected events occurs at the operational level.

3) The event causes a distortion in operational plans that the decision makers have to report to an ODSS (These specifics events have been predefined according to the literature review of Section 3)

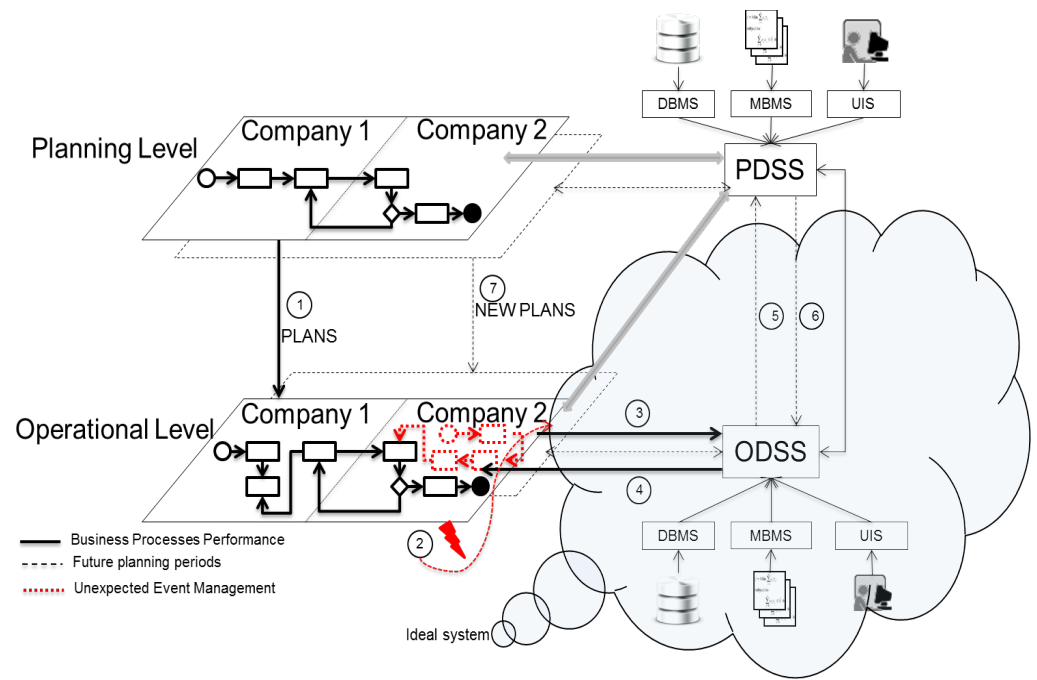

Fig. 1. Risk management model for HPP

4) The ODSS system must provide an alternative solution based on specific rules, past experiences or models. The ODSS has to be flexible and provide fast and feasible solutions at the operational level.

5) At the same time, the solution must be relayed to the upper level, because the solution has changed the inputs to decisions made at the planning level.

6) The PDSS modifies the decision model in order to handle the specific event in the future in long term basis; this modification is reported to the ODSS that storage the solution information into the application. In this way, any decision makers belonging to the collaborative network, can access through the ODSS to this information in real time, allowing them sharing vital information to help them to take better decisions when an event occurs.

7) PDSS will run again with this feedback and propose new plans for subsequent periods. The new plans are sent to the operational level that has already taken into account the impact of the event. 
This model represents widely, how is our vision to handle different kind of unexpected events through the support of an ODSS that allows decision makers to access in real time to solution alternatives that occurred in the past as a mean to provide with accurate, validated and measurable information for a specific event, helping to decision makers gather, filter and analysing information that enable making better decisions when a new unexpected event occurs. This information can be accessed by any of the decisions makers belonging to the collaborative network, allowing transfer and generation of knowledge.

One of the limitations is the kind of unexpected events analysed. The unexpected events that have been analysed (Section 2.1) do not relate soft and catastrophic issues. Soft issues associated to availability of personnel and their level of competence. Catastrophic issues associated to earthquakes, adverse weather conditions, terrorist attacks and political conflicts.

\section{Mapping the IEA framework to the risk management model in HPP}

The framework described in Section 2.3 is made up of 18 building blocks. These building blocks are represented in the model proposed in Section 3. Figure 2 shows how the 18 building blocks of the proposed IEA framework represents the problem of handling unexpected events in HPP and how they are described in each of the elements of the model. This shows how the IEA framework embeds the elements needed to describe the problem of unexpected events in HPP.

Each building block is represented in a rectangle with borders depending on which modelling view it is associated with. Thus:

-Domain represents the boundaries of the $\mathrm{CN}$ in the collaborative context of hierarchical production planning to solve the problem of unexpected events handling. -Stakeholders represent the number or nodes in the $\mathrm{CN}$ that participate in the collaborative domain.

-Organizational cell represents the teams of the $\mathrm{CN}$.

-Organizational unit represents the workstation of the $\mathrm{CN}$ and its roles. Each unit must belong to at least one cell and each team must have at least one member.

-Resources represent all those physical resources necessary to carry out the operation of the $\mathrm{CN}$.

-Worker represents a member from each stakeholder that participates in the collaborative process. The difference between worker and organizational unit is that the latest is related to the $\mathrm{CN}$ and worker is related to each stakeholder.

-Business strategy represents the mission, vision, values, goals, strategy, plans, critical success factors, policies and parameters of the $\mathrm{CN}$ that are agreed at a business level and have to be aligned with the IS/IT strategy.

-IS/IT strategy represents policies and parameters of the $\mathrm{CN}$ that are agreed at the technological level and have to be aligned with the business strategy.

-Objectives represent the goals of the $\mathrm{CN}$ for modelling the domain. 


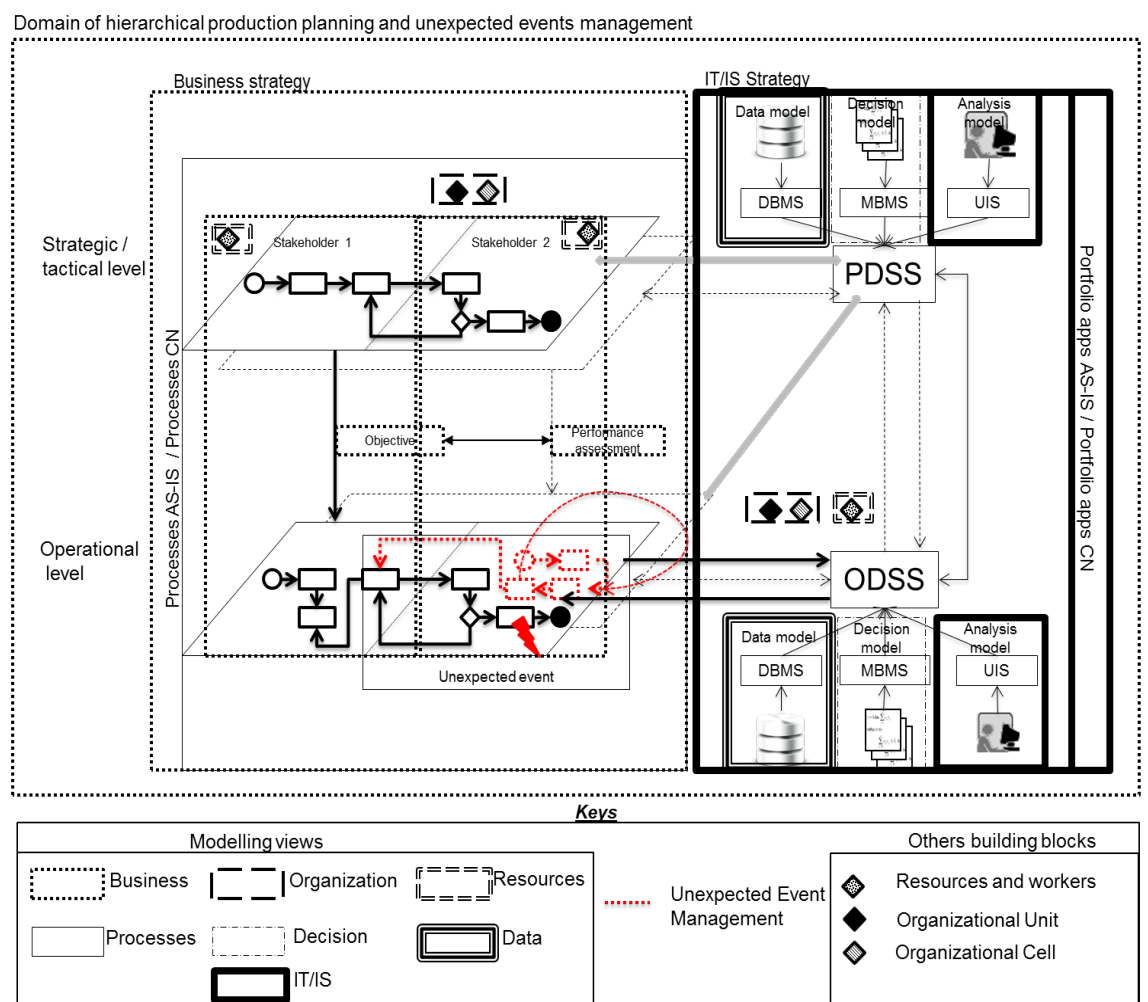

Fig. 2. Mapping IEA framework validation to risk management model in HPP

-Performance assessment helps to measure the performance of the $\mathrm{CN}$ through Key Performance Indicators (KPIs) that are assigned to measure each of the objectives of the $\mathrm{CN}$.

-AS-IS process defines at a macro-level the processes that are currently being developed in the domain of the $\mathrm{CN}$ at a local level.

- $\mathrm{CN}$ process defines the processes TO-BE of the $\mathrm{CN}$ in the global domain.

-Unexpected events allow establishing the management to support the decision process when unexpected events occur that affect production planning; there are four different origins of an event: customer, supplier, production and resource.

-Decision modelling, through this building block the decision models of the $\mathrm{CN}$ are defined, taking into account the organizational hierarchy of the $\mathrm{CN}$.

-Data modelling defines the data structure related to the decision modelling and its relationship with the analysis model.

-Analysis model defines the operation and interaction of decision modelling and data modelling.

-AS-IS Application Portfolio helps to identify the information associated with each current local application, and its importance to support the global operations of the $\mathrm{CN}$. 
-CN Application Portfolio represents the list of applications or services with which the $\mathrm{CN}$ supports joint business processes in a TO-BE state.

\section{Conclusions}

This paper proposes a risk management model for hierarchical production planning for a collaborative network for handling unexpected events. The paper also maps the IEA framework with the risk management model.

The key contribution is that it enables collaborative networks to address the problem of handling unexpected events in hierarchical production planning, thus ensuring management of risks at the operational level. The impact of this work is to support decision makers to respond effectively and efficiently to risk events using the operational decision support system that provides alternative solutions and contingency plans to ensure business continuity, taking into account a wide range of risk based events, their impact and duration. As the model is currently being evaluated in a collaborative network in the Spanish ceramic tile sector, the collected results will provide the necessary information for hypothesis validation and research question satisfaction. There are some limitations relating to the kind of unexpected events analyzed that must be taken into account for future research including, but not limited to: the soft and catastrophic events. The initial findings suggest that the proposed model is a good representation of hierarchical production planning and unexpected events handling for risk management, at the conceptual level.

\section{Acknowledgments}

This paper has been developed as a result of a mobility stay funded by the Erasmus + Mundus in framework of Traineeship Program. This research has been carried out in the framework of the project ADENPRO-PJP (Ref. PAID-06-21) funded by the Universitat Politècnica de València

\section{References}

1. Camarinha-Matos, L., Afsarmanesh, H., Ollus, M.: ECOLEAD and CNO base concepts. In L.M., C.-M., Afsarmanesh, H., Ollus, M., eds.: Methods and tools for collaborative networked organizations. Springer (2008)

2. Vargas, A., Boza, A., Cuenca, A., Ortiz, A.: Towards a Framework for Inter-Enterprise Architecture to Boost Collaborative Networks. In: On the Move to Meaningful Internet Systems: OTM 2013 Workshops. LNCS, vol. 8186, pp. 179-188, (2013)

3. Vicens, E., Alemany, M., Andrés, C., Guarch, J.: A design and application methodology for hierarchical production planning decision support systems in an enterprise integration context. International Journal of Production Economics. 74(1), 5-20 (2001) 
Risk management in hierarchical production planning using inter-enterprise architecture

4. Boza, A., Ortiz, A., Vicens, E., Poler, R.: A Framework for a Decision Support System in a Hierarchical Extended Enterprise Decision Context. LNBIP, vol.38, pp. 113-124 (2009)

5. Jüngen, F., Kowalczyk, W.: An intelligent interactive Project Management Support System. European Journal of Operational Research 84(1), 60-81 (1995)

6. Borghesi, A., Gaudenzi, B.: Operational Risk and Supply Chain Risk Management. In: Risk Management, Milan 117-137 (2013)

7. Darmoul, S., Pierreval, H., Hajri-Gabouj, S.: Handling disruptions in manufacturing systems: An immune perspective. Engineering Applications of Artificial Intelligence, 26, 110-121 (2013)

8. Bearzotti, L., Salomone, E., Chiotti, O.: An autonomous multi-agent approach to supply chain event management. International Journal of Production Economics 135(1), 468-478 (2012)

9. Boza, A., Cortes, B., Cuenca, L., Alarcón, F.: Internet of things applications in production systems. In: 17th international conference on enterprise information systems (ICEIS), Barcelona (2015)

10. Al-Kassab, J., Ouertani, Z., Schiuma, G., Neely, A.: Information visualization to support management decisions. International Journal of Information Technology \& Decision Making, 13(2) (2014)

11. Weinstein, L., Chung, C.: Integrating maintenance and production decision in a hierarchical production planning environment. Computers \& Operation Research 26(10), 1059-1074 (1999)

12. Hurtubise, S., Olivier, C., Gharbi, A.: Planning tools for managing the supply chain. Computers \& Industrial Engineering 46(4), 763-779 (2004)

13. Vargas, A., Boza, A., Cuenca, L., Sacala, I.: Inter-Enterprise Architecture and Internet of the Future. In : Technological Innovation for the Internet of Things 394, pp. 25-32. Springer Berlin Heidelberg. (2013)

14. Cuenca, L., Boza, A., Ortiz, A.: An enterprise engineering approach for the alignment of business and information technology strategy. Int. J. Computer Integrated Manufacturing 24(11), 974-992 (2011)

15. Vargas, A., Boza, A., Cuenca, L.: Towards Interoperability through Inter-Enterprise Collaboration Architectures. In: OTM 2011 Workshops LNCS, vol.7046, pp. 102-111, Springer, Berlin (2011)

16. Bernard, S.: An introduction to enterprise architecture. AuthorHouse (2012)

17. Vargas, A., Boza, A., Cuenca, L., Ortiz, A.: Using inter enterprise architecture as an instrument for decision-making under the arrival of unexpected events in hierarchical production planning. Int. J. Engineering Management and Economics 5(1/2), 73-88 (2015)

17. Vargas, A., Boza, A., Cuenca, L., Ortiz, A.: Using inter enterprise architecture as an instrument for decision-making under the arrival of unexpected events in hierarchical production planning. Int. J. Engineering Management and Economics 5(1/2), 73-88 (2015)

18. Ortiz, A., Lario, F., Ros, L.: Enterprise Integration-Business Processes Integrated Management: a proposal for a methodology to develop Enterprise Integration Programs, Computers in Industry, 40, 155-171 (1999). 